\title{
Investigation of the Role of the University in Students' Academic Self Confidence, University of Guilan, Faculty of Humanities
}

\author{
Abbas Sadeghi' ${ }^{1}$ Gholam Hossein Niayfar ${ }^{2}$, Setareh Azizi², Dors Aslan Nejad², \\ Maryam Babaei ${ }^{2}$ \\ ${ }^{1}$ Department of Counselling, University of Guilan, Rasht, Iran \\ ${ }^{2}$ Rasht, Iran \\ Email: asadeghi1394@gmail.com, Niayfar67@gmail.com, setarehazizi@gmail.com,dorsa1990@gmail.com, \\ m_babaei93@yahoo.com
}

Received 6 June 2016; accepted 9 July 2016; published 12 July 2016

Copyright $@ 2016$ by authors and Scientific Research Publishing Inc.

This work is licensed under the Creative Commons Attribution International License (CC BY). http://creativecommons.org/licenses/by/4.0/

(c) (i) Open Access

\section{Abstract}

The main goal of the research was to investigate the role of university students' self-confidence and from about 3000 students, 341 persons were selected by using Kerjecie and Morgan table and classical sampling method. 153 persons filled the inventories which its validity was confirmed through behavioral sciences academic staffs' viewpoints at university and its reliability was obtained through Cronbach Alpha Coefficient (0.83). The research results indicated that gender, age, being native and non-native, didn't make any significant differences in their discretion to prioritize effective factors on academic self-confidence, while students' academic level was considered as an effective factor. BA students believe that moral and material incentives are the most important factors of their academic self-confidence to participate in research activities while MA students believe that they will acquire academic self-confidence if conducting research activities results in their selection as the top students. Also, Ph.D. students looked for this self-confidence through specific academic activities like edition of scientific papers and participation in joint research projects with community. Therefore, it can be concluded that notice and implement of the right and appropriate policies by the two institutions of university and research are necessary for building academic self-confidence in students.

\section{Keywords}

University, Research, Academic Self-Confidence, Science

How to cite this paper: Sadeghi, A., Niayfar, G. H., Azizi, S., Nejad, D. A., \& Babaei, M. (2016). Investigation of the Role of the University in Students' Academic Self Confidence, University of Guilan, Faculty of Humanities. Sociology Mind, 6, 130139. http://dx.doi.org/10.4236/sm.2016.63011 


\section{Introduction}

Science production is defined as everything that goes back to universities and research centers. In fact, research and science production are a knowledge that comes in conflict with cases and it can be stated that science production and promotion of research morale are considered the most important cases in university values that finally result in reinforcing self-confidence morale and self-actualization.

According to Bonnen (1998), research is one of the factors and or in fact super system of knowledge and plays an important role in development and integration of knowledge, information and technology based on knowledge management approach. It seems that universities and higher education centers are conceded as research activists and bear an important role in academic research function. Also, skilled and expert manpower is the key and irrefutable factor in economic and social development. In fact, investment in supplying human researches leads to economic and social development, meets country's need from foreign countries in necessary techniques and expertise and provides fields. On the other hand, important of agricultural sector in every society is not less than other industrial and manufacturing sections and investment in this sector can result in economic growth and development. On the most important cases, investment is creating self-confidence and self-actualization science production. It means that everything which goes back to universities and research centers now is in highly agitated state. During revolution so far, quantity-oriented has damaged hard to the profession of science and university. All fields of university and production of science are not equally developed among basic science. Physics may reach conclusion as soon as possible. But biology and geology still have many primary problems. Medical science and agricultural engineering are also in the same state.

Safi limited management positions in the country in 12 categories. He believes that although there are limited legal and regulatory positions in limited positions in scientific, informational, communications, finance, organize and restrictions (Safi, 2001).

According to Xuan et al. (1989), research is a part of future changes in university and production of science in finance group and credits of research and development. In this area, private sector share is very small. The need to reach the threshold is activating the private sector in this case. We expect in the next few decades that capital will be made by production of science and development of new technologies which its expert owners spend money intensively for research. Also existing state industries don't still believe to activate the sector of production and development. If they have established such a sector, it's due to copy from industrialized countries. Therefore, regarding research state in public and private sectors and university trainings, it's unlikely to see developments from scientific and technological aspect over the next twenty years. Comparative indices show management on a global scale in the enough indicators of utility. Compared to other countries in the region, Turkey has a considerable distance from Iran, the first official to be allocated (Sabori, 2006).

\subsection{University and Researches}

University service is any activity (education, research and consulting) beyond the conventional responsibilities at the university. In fact, the result of this work, production of knowledge and practical utility services needed for community along with its development and spreading to interested and poor community is in the form of non-publication of research findings and university academic information. Hansen (1989) believes that these services have made conscious commitment for university to achieve human development in national and local levels and seek to meet the needs in international, regional, provincial and local level. But Shabani (1992) argues that words such as public services, community services, continuing education and continuing studied that have been applied in different universities, are used for the concept of university services.

The importance of research in the development of communities is no secret, as advanced societies, your position more than anything because of the expansion, deepening and development of research know (Paryad, 2004).

Research and production of science is a knowledge that will be created in conflicts with case productions of science and promotion of research morale are the main cases university values. Before the Second World War, more research was conducted to developed knowledge. During the war, the importance of creating cohesive link between achieved knowledge by theoretical research activities and their applications was placed in a special priority by releasing the link between military power and advanced technologies of countries at war. Increasing social demand along with the growth and complexity of needs, caused the need to new appliances and equipment and complexity of equipment. So it can be stated that research and production of university science is as the main engine of economic growth in developed countries in training specialists in administration and research 
issues. One of the results of education at universities, was training capable and efficient researches. Fundamental researches played a main role in guiding universities for discovering the basic facts and thinking and also applied researches provided the achieved result for community to improve the standards of people life and security. Fundamental and practical researches in different fields play a vital role in people life developing and expanding health, treatment, education in advanced countries. There for, standards of people life will not improve without research and scientific progress.

By changing the name of ministry of higher education to ministry of science, research and technology and also changing its structure, Tran has been aware of his role as the main factor of supporting the science, research and technology. I these issues are considered as the main factor of development in a country, but achieving science and technology is more complex and complicated than theoretical discussions. We should have necessary strategies to improve people life and national security by changing the attitude toward science and technology. Although Van den Hoogen (1989) believes that possibility of academic autonomy and freedom is endangered by supplying service to community and its reason is the possible involvement of these institutes in political and social issues, but it should be noticed that university seeks to its community needs in the process of curriculum and research issues and provides opportunities for participation of academics and students by delivery of services to communities. Students may observe the social issues closely through direct contact with the community and obtain more and more realistic information for conducting their researches and studies. Unfortunately with regard to different issues in Iran, university has not have comprehensive, systematic and permanent participation in executive area and such of these researches, because notional this case is very essential for development and productivity of two higher education and research institutions.

Nowadays various academic fields play the role of culture-building for different reasons as an education and cultural institution. Culture-building doesn't mean transforming the existing culture or creating new cultures, but it means to concentrate on assessing other cultures and selecting and introducing their harmonious existence with the structure of indigenous culture. In this case, university can process the cultures and social criticism and is the most important educational institution in cultures development by training capable and educated persons and elites of a community (Shiri, 2011).

In fact, university should play role in research system in the framework of its mission in three functional areas of education, research and outreach services of university. We could mention to multiple mechanisms based three functions of university, in order to achieve an interactive participation and stable systematic participation based on studies, reviews and experiences of various countries. Ministry of culture and higher education (1977) emphasize that university is responsible for training and supplying skilled and expert subjects of other sectors based on its educational function. So based on this function, university should train necessary skilled and expert individuals in research sector. This function is effective and useful in research area when the active students could be trained based on the requirements of research sector and attempt to solve those issues. This function doesn't quickly meet the needs of research due to the nature of time for training the educational human resources, but it's necessary for near future.

\subsection{University and Academic Self-Confidence}

Self-confidence is one of the human basic needs that is effective in his character evolution and is a belief that person has toward himself and abilities. It's feeling of self-esteem, ability and understanding the realistic self that avoided from disappointment and despair and having a false impression of the capabilities. In addition to confide his self-confidence, ability to perform activities of self-esteem, too. What we know about your feature called self-evaluation and self-esteem we introduced these features (Burger, 2001).

According to Karimiyan (2009) self-confidence means finding self-based on fact and as it is. Self-concept is person's comprehensive attitude toward himself/herself and everything comes from the question of “who am I?” characteristics such as hardworking, intelligence, sympathy, bravery, and self-concept are not stable and unchangeable, but it's a belief that is created as the experimental result for person and becomes his firs look to self.

Humans can either positive or negative assessment of their own. Children who have positive feelings toward and their own features, better compatibility in school (Rice, 2001).

Albert Bandora defines the self-confidence as person's belief in ability to do special works successfully. (Hesline \& Klehe, 2006).

Cultural self-confidence is a kind of person's attitude towards his community culture, if this attitude is positive it's called Cultural self-confidence. Cultural self-confidence is an issue that its process and recognition can 
be useful; and effective for awareness and growth and development of society especially for young generation. Generally, person and society require cultural nutrition depend on their state and position.

Improvement of awareness level in society increases this need some examples of cultural losses are superficiality, short-sighted and simple thoughts in analysis and relying on outside subjects. If culture is observed as the biggest support in dominance over existing difficulty, no doubt the roe of training can be ignored in promotion and enhancement of culture. University is an important and effective institution in proper transforming of cultural factors to students and delivers some services to cultural (Shiri, 2011).

self-confidence is related to inner sensation of every person about capability and personal value of that person-Respect to self is considered based on human general characteristics that person has them and personal value of life outcome is according to personal intend and principals.

Self-esteem is the degree of approval and support and value that person feels toward himself and or the judgment which the person has toward himself (Smith et al., 2002). Prerequisite for Self-esteem is having a feeling of being good about self and belief in that others also respect and pay much attention toward him (Pepper, Leddy, \& Pepper, 2001). Development of Self-esteem is much related to social factors that person experiences during his life. Social factors are along with person from the birth and are determinant of ideas, attitudes and beliefs about the person himself. Social factors that cause's pride is frequently obtained through acquiring success, ability, outstanding sport activities and business activities (Spade, 2007).

Various variables are effective in self-esteem which is:

1) Sexual variables; 2) Kinship variables; 3) healthy experiences 4) life events (Trzesniewski et al. 2010).

Biyabangard (1997) considered the self-esteem conceptual which can be defined as a value that we put on ourselves that is equivalent with feeling of valuation. Self-esteem can be a flexibility which is how we look and value on ourselves in the most basic mental levels. He emphasizes on emotional stability and personal value on self-perception. Shamlo (1995) considers it as evaluation of evidence that person has toward his valuation, that is a kind of entity valuation. In fact he knows the self-esteem as a personal judgment about worth or worthlessness, acceptance or non-acceptance of self which appears is his attitude. Also Golestan Hashemi (1995) believes that people can change their life through their mental pictures. Self-confidence is pretension of personal value and closeness feeling that its final goal is to reach the perception of competence and aptitude but generally self-confidence is the real expectation of every person from his characteristics and abilities which is gained in his previous experiences and result in success in different conditions of life and proper expectation of person from himself. Studies show that between self-esteem, self-efficacy and self-esteem and culture there is a community. In other words, part of how people feel about themselves, the culture and practices breeding and training to the community is concerned (Shimizu \& Pelham, 2004).

Self-confidence is confidence in abilities to do the task which is the reason of progress and promotion in human, self-esteem is the prerequisite of self-confidence which means how much each person puts value on self. According to Branden (Translation of Ghareh Daghi) (2006) self-esteem is comprised of two related parts, one is having self-confidence in dealing with life challenges, belief in the ability itself and the other is having competence in happiness, self-respect and self-esteem, self-esteem is a feeling that person has from himself and puts value on himself. Setoodeh (1997) believes that self-esteem has two related aspects that includes self-confidence with feeling of efficacy and self-respect or feeling of valuation. One of the important factors in satisfaction from life and also the best environment in human life is promotion of self-esteem-low self-esteem causes that person conceals his real self with embarrassment, reveals defensive states and inhibits to flourish the person's ability.

By helping sound self-esteem, It's not needed the person conceals from himself, but he controls his way of life and will not be inactive. Sound self-esteem helps person to believe in himself and loves himself and comes true his dreams and makes his future. In fact person with Sound self-esteem considers himself with self-confidence and relax, use his talents and enjoys life. He has positive attitudes world and other persons also put value on him.

In the other words, individuals with high self-confidence have desired self-judgment in mind (Tahmasbi, 2014).

The difference between self-perceived confidence (an objective picture of himself) and ideal self (what a person knows or would like to have value) stems so that the distance between these two leads to low self-esteem. And, the differences are low, indicating high confidence (Hurst et al., 1997).

If authorities seek to provide a pattern for development of country, no doubt maintenance and development of universities should be considered as a starting point of this case and seek to create more capacities for maintaining and attracting these centers that certainly one of methods to attention to university and students is supporting their trainings and creating motivation in them for conducting research activities and finally creating self-con- 
fidence morale in them that needs proper and basic planning like every other institutional activities. So, active participation and interactive cooperation of universities and research centers is a deniable necessity in the process of developing university and creating academic self-confidence, because universities seek to meet the needs of their community in the process of curriculum and research issues and provide effect of these universities, services is to become familiar with salient and favorable issues society. Also, this phenomenon can be effective in prompting the state of university, its efficacy and updating and also causes that community benefits from facilities, ability and capacity of university and is effective in developing the amount of community trust in university, enhancing the opportunity of employment and applying and employment of result and increasing the service to students and finally enhancing their self-confidence.

\subsection{Research Purposes}

This research main goal was to investigate the role of university in students' academic self-confidence at university of Guilan and its secondary goals were:

-Prioritizing the effective factors in students' academic self-confidence.

-Awareness from the effect of respondents' gender in prioritizing the effective factors on students' academic self-confidence.

-Awareness from the effect of respondents academic level in prioritizing the effective factors on students' academic self-confidence.

\section{Methodology}

Research method in this research is analytic-descriptive and statistical population includes students at faculty of humanities in university of Guilan that are about 3000 person which 341 persons were selected through classical sampling method and based on kerjecie and Morgan table (1970). Among them 153 persons filled the questionnaire. This research instrument was a questionnaire with 15 questions in Likert spectrum that its validity was confirmed through survey of behavioral science professors and its reliability was obtained through Cronbach's Alpha coefficient (0/83). Analysis of data was also analyzed in two stages, descriptive (frequency, standard deviation and frequency percent) and inferential (Test of comparing the means through t-test) and F-test and software SPSS. Meanwhile, all the participants had been informed prior the data collection.

\section{Findings}

\subsection{Descriptive Statistics}

Investigation the frequency of answers showed that 0.97 respondents (21 persons) were educated in BA level, 0.18 (28 students) in MA level and 0.3 in Ph.D. Severity of the effect of effective factors on students' academic self-confidence has been brought in Table 1 based on research inventory and respondents' opinion:

According to above table, it's clear that almost most respondents consider these factors useful in creating motivation for research activities and them self-confidence of skills and academic abilities But based on respondent' opinion, those factors that have the most effect in creating academic self-confidence are brought in Table 2.

According to achieved result from above table (Table 3), it can be concluded that the most important factor of academic self-confidence.

Table 1. Demographic characteristics (gender, age and native or none native).

\begin{tabular}{ccccc}
\hline & & & Total \\
\hline Gender & Male & 66 & 153 \\
& Fgemale & $19-23$ & 87 & 76 \\
& Upper 24 & 77 & 153 \\
Native or non-native & Native & 107 & 153 \\
\hline
\end{tabular}


Table 2. Frequency percent of effective factors on students’ academic self-confidence.

\begin{tabular}{lccc}
\hline \multicolumn{1}{c}{ Factors severity of effect } & high & Average & Low \\
\hline Conducting study plans with students' valid participation. & 103 & 39 & 11 \\
Students' participation in research center meetings in the role of counselor. & 49 & 44 & 15 \\
Creating electronic groups in college for counseling with research sector. & 25 & 44 & 57 \\
Invitation to Students' visit from research projects. & 95 & 40 & 81 \\
Considering research activities in students' tasks. & 47 & 65 & 23 \\
Conducting the policy of de-concentration in higher education to assign more authorities to students. & 99 & 37 & 17 \\
Encourage students to communicate with research institutions. & 111 & 32 & 10 \\
Holding common meetings in the café of research activities in national and regional level. & 89 & 50 & 14 \\
Benefit from skilled experts in research institutions for teaching a part of university lessons. & 45 & 65 & 43 \\
Using facilities and convenience for students' participation in research activities. & 10 & 84 & 5 \\
Considering students' cooperation in research as an important indicator in selecting top students. & 712 & 19 & 7 \\
Benefit from research service of university through drawing up contract with environmental institution. & 710 & 53 & 11 \\
Creating financial and moral motivations for students' participation in conducting research activities. & 121 & 92 & 3 \\
Training students to conduct research activities. & 88 & 57 & 8 \\
Providing regulation to improve students' academic knowledge like professors. & 511 & 22 & 16 \\
\hline
\end{tabular}

Table 3. Prioritizing the effective factors on students' self-confidence.

\begin{tabular}{clc}
\hline Priority & \multicolumn{1}{c}{ Traits } & Frequency Percent \\
\hline 1 & Considering students' cooperation in research as an important indicator in selecting top student. & $87 \%$ \\
2 & $\begin{array}{l}\text { Creating financial and moral motivations for students' participation in conducting in conducting } \\
\text { research activities. }\end{array}$ & $83 \%$ \\
3 & Proving regulation to improve students' academic knowledge like professors. & $79 \%$ \\
4 & Encourage students to communicate with research institutions. & $75 \%$ \\
5 & Benefit from research services of university through drawing up contract with environmental. & $70 \%$ \\
\hline
\end{tabular}

In students and considering students' cooperation with research was as an important indicator of selecting to students and creating financial and moral motivations for students' participation activities and perform their skills and abilities.

\subsection{Inferential Statistics}

After prioritizing important factors in students' academic self-confidence through descriptive statistics, it in this stage was found on students' comparison from students' gender and academic level.

1) Comparison of respondents' attitude from gender aspect with prioritizing effective factors on academic self-confidence

\section{Research hypothesis 1}

There is a difference between students' gender and amount of their recognition in prioritizing the effective factors on academic Self-confidence. This comparison is conducted through applying T-test (Table 4).

The result of Table 4 shows that this hypothesis was rejected and there is a significant difference among individuals' gender and their recognition in prioritizing the effective factors on academic Self-confidence.

2) Comparison of respondent' attitude from native and non-native aspect with prioritizing the effective factors on their academic Self-confidence

This hypothesis is consistent with research Asgari et al (2008); Shaghagi \& Haris (2010).

Research hypothesis 2

There is a difference between students' native and the amount of their recognition in prioritizing the effective factors on academic Self-confidence. This comparison was conducted through applying T-test. 
Above table shows that this hypothesis was rejected and there is a significant difference between students' native and non-native and their recognition in prioritizing the effective factors on academic self-confidence (Table 5).

3) Comparison the respondents' attitude from age aspect with prioritizing the effective factors on academic self-confidence

Research hypothesis 3:

There is a difference between ages of 19 to upper 23 and 24 in students and their recognition in prioritizing the effective factors on academic self-confidence. This comparison was conducted through applying T-test (Table 6).

Based on above table results, this hypothesis was rejected and there is a significant difference between students' age and their revocation in prioritizing the effective factors on academic self-confidence.

4) Investigation the amount of respondents' agreement from academic level with prioritizing the effective factors on self-confidence

\section{Research hypothesis 4}

There is difference between students' academic level and amount of their recognition in prioritizing the effective factors on academic self-confidence. This comparison was conducted through T-test. This hypothesis is consistent with research Asgari et al. (2008), Javadi Nezhad (2001).

This research results showed that difference in students' academic level is effective in their recognition for prioritizing the effective factors in academic self-confidence. So Toki-test was used to exact investigation of difference (Table 7).

Above table results show that students' academic level is an effective factor in their recognition for prioritizing the effective factors on academic self-confidence. Based this, BA students believe that financial and spiritual encouragements is the most important factor in their academic self-confidence for participating in research activities. While MA students believe that they acquire academic self-confidence when conducting research activities result in their selection as top students and PHD students consider their academic self-confidence as an encouragement for communicating with research institutions, because, they believe this factor can play considerable role in their job future.

Table 4. Comparison the mean of respondents' opinion about prioritizing the effective factors on academic self-confidence.

\begin{tabular}{cccc}
\hline Gender variable & Mean & Standard deviation & t-test \\
Male & 8.43 & 3.19 & 0.65 \\
Female & 49 & 4.52 & 0.43 \\
\hline
\end{tabular}

Table 5. Comparison the mean of respondents’ opinion about prioritizing the effective factors on academic self-confidence.

\begin{tabular}{ccccc}
\hline Native and non-native variable & Mean & Standard deviation & t-test & Sig level \\
\hline Native & 5.24 & 3.23 & 0.77 \\
Non-native & 36 & 4.53 & 0.45 \\
\hline
\end{tabular}

Table 6. Comparison the mean of respondents’ opinion about prioritizing the effective factors on academic self-confidence.

\begin{tabular}{ccccc}
\hline Age variable & Mean & Standard deviation & t-test & Sig level \\
\hline 23-19 & 27.23 & 3.89 & 0.55 & 0.22 \\
Upper 24 & 37 & 4.44 & & 0.22 \\
\hline
\end{tabular}

Table 7. Toki test used to determine the differences of students' academic level in prioritizing the effective factor on academic self-confidence.

\begin{tabular}{cccc}
\hline Level & Level & Mean difference & Sig level \\
Level & MA & $25.5^{*}$ & 0.001 \\
Level & PHD & $61.4^{*}$ & 0.006 \\
Level & MA & $25 / 5^{*}$ & 0.001 \\
Level & PHD & $0.64^{*}$ & 53.08 \\
Level & BA & $61.4^{*}$ & 0.006 \\
Level & MA & $0.64^{*}$ & 53.08 \\
\hline
\end{tabular}




\section{Discussions and Conclusion}

Regarding this research findings, we can conclude that Students in three levels, consider different factors effective on their academic self-confidence and the factor which has the most effect on their academic self-confidence is financial and spiritual encouragements and communication with research Centers. So it can be concluded that university communication with research centers can have positive and considerable outcomes for all systems and individuals. Based On the goals of three kinds of education, research and Up-date Services functions in research area, university role is:

1) Educational function of the university: educating good students and agreement with community requirements and research sector.

2) Research function of University: conducting academic researches for developing science and research.

3) Up-date function of university: education, research, counseling according to importance and university participation in research area in Iran conditions, it can be stated that regarding and conducting proper and appropriate policy from two institutions of university and research centers is necessary for creating self-actualization and self-confidence in students. In fact, political tasks are facilitators and grounds for conducting the effective tasks on participation of university in research area. There were some limitations such as:

-There were no enough understanding about the concept of Academic self-confidence.

-It was limited to the Faculty of Humanities students, and

-Some mistakes about the concept of Native and non-native national or according to province.

\section{Recommendations}

So, by determining the necessity of conducting research in this area, it's recommended that a close relationship will be created between Universities and research centers and following cases are recommended for conducting this case:

-Participation of universities in preparing the strategic policies of research centers in national and regional level.

-Creating a common office for cooperating the faculty of humanities with research centers.

-Creating centers of academic counseling in faculty of humanities for Students and researches.

-And finally making the research centers necessary for participating the faculty of humanities in education and research issues.

\section{References}

Asgari, P. et al. (2008) The Relationship between Happiness, Self-Actualization and Androgyny Mental Health and Academic Performance of Male and Female Students. Azad University of Ahvaz, Psychological Knowledge and Research, Number 33.

Biyabangard, E. (1997) Increasing Methods of Self-Esteem in Children and Young Adults (4th ed.). Tehran: Parents Meeting Press.

Bonnen, J. T. (1998). The Land Grant College Idea and Evolving Outreach University. New York: Garland Publications.

Branden, N. N. (2006). Self-Confidence Psychology. Translation of Mehdi Gharache Daghi, Tehran: Nokhostean Press.Confidence in Academic Communities and Universities from Quran and Narrative's Perspective, Recognition Studies at Islamic Free University, Number 34, 81-99.

Burger, J. M. (2001) Personality (5th ed.). Belmont, CA: Wadsworth.

Golestan Hashemi, S. M. (1995) Self-Concept and Academic Progress. Peyvand, Number 188. Tehran: Iran Parents’ Meeting Press.

Hansen, G. E. (1989). Universities for Development: Lessons for Enhancing the Role of Agricultural Universities in Developing Countries. USAID Evaluation Occasional Paper 31, Washington DC: United States Agency for International Development, Center of Development Information and Evaluation, Bueau for Program and Policy Coordination.

Hesline, P. A., \& Klehe, U. C. (2006). Self-Efficacy. In S. G. Rogelberg (Ed.), Encyclopedia of Industrial/Organizational Psychology, 2, 705-708.

Higher Education and Culture Ministry (1977). Higher Education Aspect of Academic Board Members and Students. Tehran: Research Institution and Planning of Higher Education, Statistical and Research Groups.

Hurst, D. F., Boswell, D. L., Boogaard, S. E., \& Watson, M. W. (1997). The Relationship of Self-Esteem to the Health-Related Behaviors of the Patients of a Primary Care Clinic. Archives of Family Medicine, 6, 67-70. 
http://dx.doi.org/10.1001/archfami.6.1.67

Javadi Nezhad, A. (2001). Check between Affective Family Functioning and Mental Health and Academic Performance of Girls Ahvaz. Thesis of M.A, Tehran: University of Tehran.

Karimiyan, S. A (2009). Introduction of Self-Confidence Principals. A Collection of National Congress Papers about National Self-Confidence and Academic Development. Rasht: University of Guilan, Faculty of humanities.

Leddy, S., \& Pepper, J. (2001). Conceptual Bases of Professional Nursing. Philadelphia: J.B Lippinicott Co.

Paryad, R. (2004). Structural Barriers between Faculty Research Groups Liberal Education of Universities and the West Country. Researches Higher Education and Sustainable Development, 2, 233-235.

Rice, F. P. (2001). Human Development (4th ed.). Upper Saddle River, NJ: Prentice Hall.

Sabori, A. (2005). Survey of Relationship between Mental Health and Self Confidence. In A. Saboni, Ed., Research Proceedings of the 2005 Spring and Summer Approach (No. 37, 44-48). Mental Health Journal. Isfahan: Isfahan University.

Safi, A. (2001). Importance of Research in Education, Efforts, Challenges and Future Policy. Journal of Education, No. 35.

Setoodeh, H. (1997). Social of Psychology. Tehran: Avaya Noor Press.

Shabani, H. (1992). Education Skills (Teaching Strategies and Techniques). Tehran: Semat Press.

Shaghagi \& Haris (2010). Compare the Self-Realization, Undergraduates and Graduate Students of Payame Noor University. PNU, Year 9, No. 1.

Shamlo, S. (1995). Theories of Personality. Tehran: Roshd Press.

Shimizu, M., \& Pelham, W. (2004). The Unconscious Cost of Good Fortune: Implicit and Explicit Self-Esteem, Positive Life Events, and Health. Health Psychology, 23, 101-105. http://dx.doi.org/10.1037/0278-6133.23.1.101

Shiri, T. (2011). Influence of Academic Field on Student's Cultural Self-Confidence. Communication Culture Journal, No. 4, 141-164.

Smith, E. E., Nolen-Hoeksema, S., Fredrickson, B., \& Loftus, G. (2002). Atkinson and Hilgard's Introduction to Psychology (14th ed.). New York: Wadsworth Publishing.

Spade, J. A. (2007). The Relationship between Student Bullying Behaviors and Self-Esteem. Doctoral Dissertation, Bowling Green, OH: Graduate College of Bowling Green State University.

Tahmasbi, R. et al. (2014). Investigation the Effect of Self-Confidence and Self-Esteem on Formation of Imagery in the Sepah Bank Staff, Organizational. MA Dissertation, Tehran: Tehran University.

Trzesniewski, K. H., Ulrich, O., \& Robins, R. W. (2010). Self-Esteem Development from Young Adulthood to Old Age: A Cohort-Sequential Longitudinal Study. Journal of Personality and Social Psychology, 98, 645-658. http://dx.doi.org/10.1037/a0018769

Van den Hoogen, J. M. P. (1989). Institutional Development in Higher Agricultural Education. In W. Van Der Bor, J. C. M. Shoute, \& G. A. B. Moore (Eds.), South-North Partnership in Strengthening Higher Education in Agriculture (pp. 34-43). Wageningen: Pudoc.

Xuan, V. T., \& Van Mensvoort, T. E. F. (1989). Curriculum Development for Agriculture in a Postwar Economy: The Case of Vietnam. In W. Van Der Bor, J. C. M. Shoute, \& G. A. B. Moore (Eds.), South-North Partnership in Strengthening Higher Education in Agriculture (pp. 19-26). Wageningen: Pudoc. 


\section{Appendix 1: Research Questionnaire}

\section{Dear student}

Hi

This questionnaire is designed to survey the academic self confidence in the students. Please answer all questions. Writing first and surname is not necessary. Meanwhile, all information would be confidential.

With many thanks

Dr. Abbas Sadeghi, Associate professor and the colleagues.

Dept. Counseling, Faculty of Humanities, University of Guilan,

City of Rasht

1. Individual information

Gender:

Age:

Native/non-Native:

\section{Questions}

Please circle the answer you have chosen agreement, uncertain and none agreement in the questions as follows:

\section{Items}

- Conducting study plans with students’ valid participation.

- Students' participation in research center meetings in the role of counselor.

- Creating electronic groups in college for counseling with research sector.

- Invitation to Students’ visit from research projects.

- Considering research activities in students’ tasks.

- Conducting the policy of de-concentration in higher education to assign more authorities to students.

- Encourage students to communicate with research institutions.

- Holding common meetings in the café of research activities in national and regional level.

- Benefit from skilled experts in research institutions for teaching a part of university lessons.

- Using facilities and convenience for students’ participation in research activities.

- Considering students' cooperation in research as an important indicator in selecting top students.

- Benefit from research service of university through drawing up contract with environmental institution.

- Creating financial and moral motivations for students’ participation in conducting research activities.

- Training students to conduct research activities.

- $\quad$ Providing regulation to improve students’ academic knowledge like professors.

**** If you have any other viewpoints, about students' academic self-confidence write here please 


\section{Submit or recommend next manuscript to SCIRP and we will provide best service for you:}

Accepting pre-submission inquiries through Email, Facebook, Linkedin, Twitter, etc A wide selection of journals (inclusive of 9 subjects, more than 200 journals)

Providing a 24-hour high-quality service

User-friendly online submission system

Fair and swift peer-review system

Efficient typesetting and proofreading procedure

Display of the result of downloads and visits, as well as the number of cited articles

Maximum dissemination of your research work

Submit your manuscript at: http://papersubmission.scirp.org/ 